\title{
Genistein inhibits MDA-MB-231 triple-negative breast cancer cell growth by inhibiting NF-кB activity via the Notch-1 pathway
}

\author{
HONG PAN ${ }^{1}$, WENBIN ZHOU ${ }^{1}$, WEI HE ${ }^{2}$, XIAOAN LIU ${ }^{1}$, QIANG DING $^{1}$, \\ LIJUN LING $^{1}$, XIAOMING ZHA ${ }^{1}$ and SHUI WANG ${ }^{1}$ \\ Departments of ${ }^{1}$ Breast Surgery, ${ }^{2}$ Endocrinology and Metabolism, The First Affiliated \\ Hospital of Nanjing Medical University, 210029 Nanjing, P.R. China
}

Received February 23, 2012; Accepted April 13, 2012

DOI: $10.3892 / \mathrm{ijmm} .2012 .990$

\begin{abstract}
Genistein (Gen) has been reported as a protective factor against breast cancer. However, the molecular mechanism by which Gen elicits its effects on triple-negative breast cancer cells has not been fully elucidated. In our study, the breast cancer cell line MDA-MB-231 was selected to determine the action of Gen on triple-negative breast cancer cells. MTT assay, flow cytometric analysis, siRNA transfection, western blotting and nuclear factor- $\kappa \mathrm{B}(\mathrm{NF}-\kappa \mathrm{B})$ activationnuclear translocation assay were used to address the role of $\mathrm{NF}-\kappa \mathrm{B}$ activity and the Notch-1 signaling pathway on the effects of Gen. Our study revealed that Gen elicited a dramatic effect on cell growth inhibition, in a dose-dependent and time-dependent manner. Treatment of MDA-MB-231 cells with $0,5,10$ or $20 \mu \mathrm{M}$ Gen induced apoptosis of $6.78,18.98$, 30.45 and $60.64 \%$, respectively. Exposure of MDA-MB231 cells to Gen also resulted in $\mathrm{G} 2 / \mathrm{M}$ phase accumulation of cells corresponding to $4.93,12.54,18.93$ and $30.95 \%$, respectively. Furthermore, our data demonstrated for the first time that Gen inhibited the growth of MDA-MB-231 triplenegative breast cancer cells by inhibiting NF- $\kappa \mathrm{B}$ activity via the Nocth-1 signaling pathway in a dose-dependent manner. We also found that Gen downregulated the expression of cyclin B1, Bcl-2 and Bcl-xL, possibly mediated by $\mathrm{NF}-\kappa \mathrm{B}$ activation via the Notch-1 signaling pathway. In conclusion, our results suggest that inhibition of $N F-\kappa B$ activity via the Notch-1 pathway may be a novel mechanism by which Gen suppresses the growth of triple-negative breast cancer cells. Further preclinical and clinical studies are warranted to further investigate the application of Gen for the treatment of triple-negative breast cancer.
\end{abstract}

Correspondence to: Professor Wei He, Department of Endocrinology and Metabolism, The First Affiliated Hospital of Nanjing Medical University, 300 Guangzhou Road, 210029 Nanjing, P.R. China E-mail: hewei1007@sina.cn

Key words: triple-negative breast cancer, genistein, Notch-1 signaling pathway, nuclear factor- $\mathrm{\kappa B}$

\section{Introduction}

Breast cancer is a common malignant disease in women and is the second leading cause of cancer-related deaths in the United States $(1,2)$. Although the mortality rate has declined in developed countries, a significant number of patients (3-8), whose features include the negative expression of estrogen receptor- $\alpha$ (ER- $\alpha)$, progesterone receptor (PR), and human epidermal growth factor receptor 2 (Her2) demonstrate aggressive clinical behavior and poor outcome. This subgroup of breast cancer patients are defined as triple-negative breast cancer patients (TNBC).

Notably, TNBC represents approximately $15 \%$ of all breast cancers (3), and is diagnosed more frequently in younger and premenopausal women (4-8). Patients with TNBC have the disadvantage of not benefiting from currently available receptor-targeted systemic therapy, such as hormonal and trastuzumab-based therapies. Thus, chemotherapeutic regimens have been the mainstay available treatments which always bring variable efficacy. Therefore, the development of novel molecular targeted therapeutic strategies is required.

Genistein (Gen), one of the major soy isoflavones in soy products, was reported as a protective factor against breast cancer (9). Epidemiological evidence strongly supports that Asian women, who consume a diet high in soy products, have a relatively low incidence of breast cancer and risk of breast cancer recurrence (10-13). Previous studies have suggested that Gen can inhibit the cell cycle, induce cell apoptosis, and promote cell differentiation for TNBC breast cancer cells $(14,15)$. Gen, a relative nontoxic natural agent, may become another therapeutic option for the treatment of breast cancer, especially for TNBC. However, the mechanisms of its action remain unclear.

Notch-1 signaling pathway plays a critical role in breast cancer (16). Importantly, the study indicated that targeting Notch signaling pathway with $\gamma$ secretase inhibitors (GSI) should be explored to further improve the survival rate of TNBC patients. Nonetheless, GSI may have widespread adverse effects in vivo because proteases participate in a wide array of cellular functions (17). It is essential to investigate whether Gen is an efficient agent substituting for GSI to overcome these limitations. Additionally, nuclear factor- $\kappa \mathrm{B}$ $(\mathrm{NF}-\kappa \mathrm{B})$ is a putative target gene of activated Notch-1 (18), 
which is another major cell growth and apoptosis regulatory pathway. In the present study, we investigated whether Gen inhibits triple-negative breast cancer MDA-MB-231 cells growth via the Nocth-1 signaling pathway.

The MDA-MB-231 cell line is a typical TNBC line. Our data demonstrate for the first time, to our knowledge, that Gen inhibits triple-negative breast cancer MDA-MB-231 cell growth by inhibiting NF- $\kappa$ B activity via the Nocth-1 signaling pathway. Our study suggests that Gen may be a potential therapeutic agent for TNBC.

\section{Materials and methods}

Cell culture. The human breast cancer cell line MDA-MB-231 was obtained from the American Tissue Culture Collection (ATCC). The cells were routinely cultured in complete medium (DMEM supplemented with 10\% fetal bovine serum, $100 \mathrm{U} / \mathrm{ml}$ penicillin, and $100 \mu \mathrm{g} / \mathrm{ml}$ streptomycin) in a $5 \% \mathrm{CO}_{2} 37^{\circ} \mathrm{C}$ incubator. Gen (Sigma, USA) was dissolved in dimethyl sulfoxide (DMSO), and was added directly to the culture media at different concentrations. The concentration of DMSO $(0.05 \%)$ in the final working solution did not interfere with cell growth. The same concentration of DMSO was present in all control cultures.

siRNA plasmid and transfection. MDA-MB-231 cells were transfected with Notch-1 siRNA, NF- $\kappa B$ siRNA and siRNA controls (GenePharma, China), using Lipofectamine 2000. One day before transfection, cells were plated in $2 \mathrm{ml}$ DMEM without antibiotics. siRNA of $5 \mu \mathrm{l}$ (final concentration $100 \mathrm{pM}$ ) and $5 \mu \mathrm{l}$ Lipofectamine 2000 were diluted in $250 \mu \mathrm{l}$ opti-MEM medium without serum separately, mixed gently and incubated for $5 \mathrm{~min}$ at room temperature. Subsequently, the diluted oligomer was combined with the diluted Lipofectamine 2000. The combination was incubated for $20 \mathrm{~min}$ at room temperature, and added to each well containing cells and medium. The medium were changed after $6 \mathrm{~h}$.

Cell growth inhibition studies by the MTT assay.MDA-MB-231 cells were seeded at a density of $5 \times 10^{3}$ cells/well in $200 \mu \mathrm{l}$ of medium in a 96-well culture plates, and cultured for $24 \mathrm{~h}$. The cells were treated with 5, 10, $20 \mu \mathrm{M}$ Gen for 24,48 and $72 \mathrm{~h}$, while control cells were cultured in medium with $0.05 \%$ DMSO. After treatment, the cells were incubated with MTT $(0.5 \mathrm{mg} / \mathrm{ml})$ at $37^{\circ} \mathrm{C}$ for $4 \mathrm{~h}$ and with DMSO at room temperature for $15 \mathrm{~min}$. The absorbance of the samples was measured at $490 \mathrm{~nm}$ on a scanning multi-well spectrophotometer. The experiment was repeated 3 times.

Quantitative apoptotic cell death assay. MDA-MB-231 cells were seeded in 6-well culture plates, and subsequently treated with 5,10 and $20 \mu \mathrm{M}$ Gen for $72 \mathrm{~h}$, while control cells received $0.05 \%$ DMSO in culture medium. After treatment, the floating and adherent cells were collected. Pooled cells were washed with phosphate-buffered saline (PBS). The cells were suspended in $100 \mu \mathrm{l}$ PBS and mixed with $5 \mu \mathrm{l}$ of Annexin V-FITC and $10 \mu 1$ of propidium iodide. The cells were analyzed with a flow cytometer after $15 \mathrm{~min}$ of incubation in the dark.

Cell cycle analyses. MDA-MB-231 cells were synchronized in $\mathrm{G} 0$ by serum starvation for $24 \mathrm{~h}$ in serum-free medium.

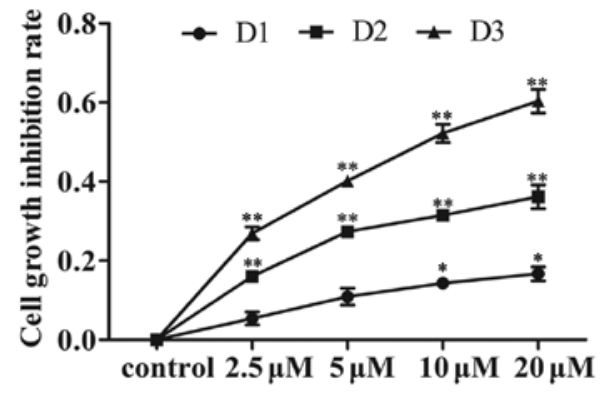

Figure 1. Effect of Gen on MDA-MB-231 cell growth. Gen inhibits cell proliferation in a time and dose-dependent manner. Cells were seeded in a 96-well culture plate at a cell density of $5 \times 10^{3}$ cells/well and treated with 0 , 5, 10 and $20 \mu \mathrm{M}$ Gen for 24, 48 and $72 \mathrm{~h}$. After treatment, cell densities were determined by the MTT assay. Each value represents the mean \pm SD $(n=6)$. Significantly different from control, ${ }^{*} \mathrm{P}<0.05,{ }^{* *} \mathrm{P}<0.01$.

Subsequently, cells were incubated in complete phenol red-free DMEM containing $10 \%$ fetal bovine serum for $72 \mathrm{~h}$ with or without various concentrations of Gen. After treatment, cells were trypsinized and washed in cold PBS twice, fixed in $70 \%$ ethanol over $6 \mathrm{~h}$ at $4^{\circ} \mathrm{C}$. The distribution of cells at different stages of the cell cycle was estimated by flow cytometric DNA analysis. The percentage of cells in each cell cycle phase (G0/ $\mathrm{G} 1, \mathrm{~S}$ or $\mathrm{G} 2 / \mathrm{M}$ ) was calculated by using Lysis II software.

Determination of $N F-\kappa B$ activity. MDA-MB-231 cells were seeded in a 6-well culture plate, and treated with $0,5,10$ and $20 \mu \mathrm{M}$ Gen for $72 \mathrm{~h}$. The cells were immunofluorescencelabeled according to the manufacturer's instructions using the NF- $\kappa \mathrm{B}$ activation-nuclear translocation assay kit (Beyotime Biotech, China). After washing and fixing, cells were incubated with a blocking buffer for $1 \mathrm{~h}$ to suppress non-specific binding. Next, cells were incubated with the primary NF- $\mathrm{BB}$ p65 antibody at $4^{\circ} \mathrm{C}$ overnight, followed by incubation with a Cy3-conjugated secondary antibody for $1 \mathrm{~h}$, then with DAPI for 5 min before observation. NF- $\mathrm{KB}$ p 65 protein and nuclei fluoresce red and blue respectively, and can be simultaneously viewed by laser confocal microscope at an excitation wavelength of $350 \mathrm{~nm}$ for DAPI and $540 \mathrm{~nm}$ for Cy3. To create a two-color image, the red and blue images were overlaid, producing pink fluorescence in areas of co-localization.

For the siRNA transfected effect, the assay was performed as described above $72 \mathrm{~h}$ after the cells were transfected with Notch-1 siRNA, NF-kB siRNA or siRNA control.

Western blotting. After treatment, cells were washed twice with cold PBS and then scraped off in $500 \mu 1$ of buffer RIPA (with PMSF) and incubated on ice for $30 \mathrm{~min}$. Then, cell lysates were centrifuged at $14,000 \mathrm{x} g$ for $15 \mathrm{~min}$, and the supernatants were stored at $-80^{\circ} \mathrm{C}$. Protein concentrations were measured by use of the BCA protein assay. The prepared proteins were boiled for $5 \mathrm{~min}$, and separated by $12 \%$ SDS-PAGE. Proteins were transferred to PVDF membranes, which were activated in methanol. The membranes were immunoblotted with anti-rabbit Notch-1 (Abcam), cyclin B1, Bcl-2, Bcl-xL (Cell Signaling Technology) and GAPDH (Santa Cruz Biotechnology, Inc.) antibody, and anti-mouse NF- $\kappa \mathrm{B}$ antibody, followed by secondary anti-mouse antibody and anti-rabbit antibody. GAPDH was used to normalize for 


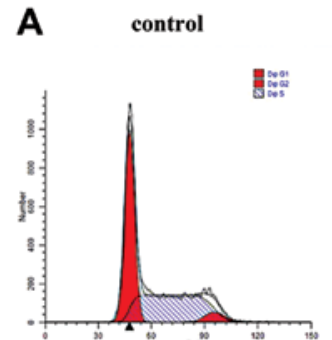

$10 \mu \mathrm{M}$

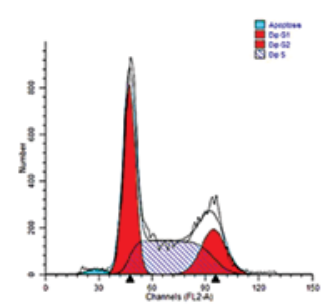

B
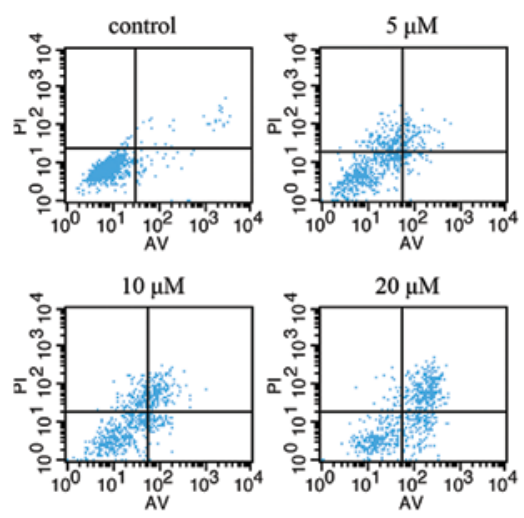

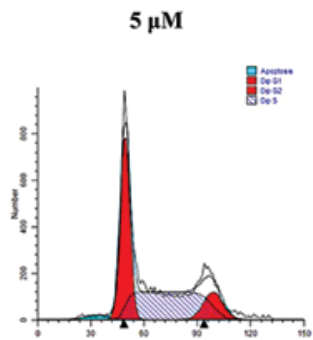

$20 \mu \mathrm{M}$
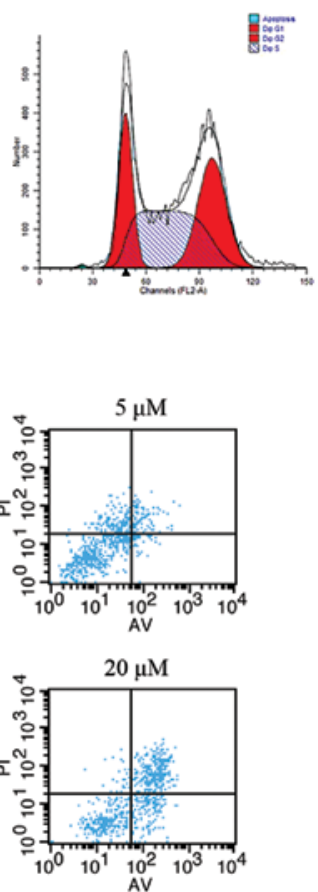
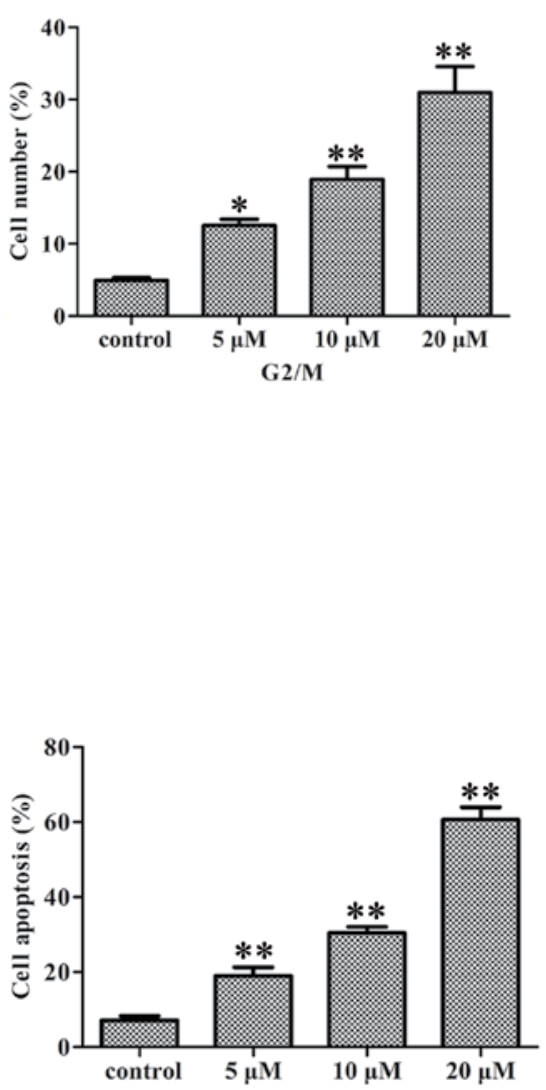

Figure 2. Effect of Gen on MDA-MB-231 cell apoptosis and cycle. (A) The cell death assay was used to measure apoptosis induced by Gen. The representative dual-parameter fluorescence histograms were derived from cell cultures exposed to various Gen concentrations, $0,5,10$ and $20 \mu \mathrm{M}$ for $72 \mathrm{~h}$. Cells were incubated with Annexin V-FITC and PI. Results are reported as an apoptotic index. Bars, mean \pm SD, ${ }^{* *} \mathrm{P}<0.01$, significantly different from control. (B) Cell cycle analyses for measuring cell cycle distribution of MDA-MB-231 cells treated with Gen. Cells were treated with $0,5,10$ and $20 \mu \mathrm{M}$ Gen for $72 \mathrm{~h}$. The percentage of cells in each cell cycle phase (G1, S and G2/M) was determined by flow cytometry. Bars, mean $\pm \mathrm{SD},{ }^{*} \mathrm{P}<0.05,{ }^{* *} \mathrm{P}<0.01$, significantly different from control.

protein loading. The membranes were probed using ECL and autoradiographed. All experiments were performed three times. The intensity of the bands was determined using densitometric analysis.

Statistical analyses. Data are expressed as means \pm standard deviation (SD). Comparisons were made between control and treatment groups. Statistical differences were analyzed using one-way ANOVA. P-value $<0.05$ was considered to indicate statistical significance.

\section{Results}

Gen inhibits proliferation in MDA-MB-231 cells. MDA-MB231 cells were exposed to Gen at concentrations of 5, 10 and $20 \mu \mathrm{M}$, while the control cells received $0.05 \%$ DMSO in the medium. Subsequently, cell proliferation was determined by the MTT assay at 24, 48 and $72 \mathrm{~h}$. A time-dependent and dosedependent inhibition of cell growth was observed (Fig. 1).

Gen induces apoptosis in MDA-MB-231 cells. MDA-MB231 cells $(0,5,10$ and $20 \mu \mathrm{M}$ Gen for $72 \mathrm{~h})$ were collected, and stained with Annexin V and propidium iodide. The Gen-induced apoptosis was investigated by flow cytometry. The result showed that Gen induced apoptosis in a dosedependent manner (Fig. 2A). The apoptosis percentages of all MDA-MB-231 cells treated with $0,5,10$ or $20 \mu \mathrm{M}$ Gen were $6.78,18.98,30.45$ and $60.64 \%$, respectively.

Gen-treated MDA-MB-231 cells arrest in the G2/M phase of the cell cycle. MDA-MB-231 cells were treated with $0,5,10$ or $20 \mu \mathrm{M}$ concentrations of Gen for $72 \mathrm{~h}$, and the cell cycle phase was determined by flow cytometry. Gen induced a significant accumulation of cells in the $\mathrm{G} 2 / \mathrm{M}$ phase of the cell cycle in a dose-dependent manner (Fig. 2B). The percentages of cells in the $\mathrm{G} 2 / \mathrm{M}$ phase of the cell cycle after treatment with $0,5,10$ or $20 \mu \mathrm{M}$ were $4.93,12.54,18.93$ and $30.95 \%$, respectively.

Gen inhibits the NF- $\kappa B$ pathway through the Notch-1 pathway in MDA-MB-231 cells

Gen inhibits Notch-1 expression. To investigate whether the Notch-1 pathway is involved in the action of Gen, western blot analysis was used to determine the status of Notch-1 in MDA-MB-231 cells treated with different concentrations of 

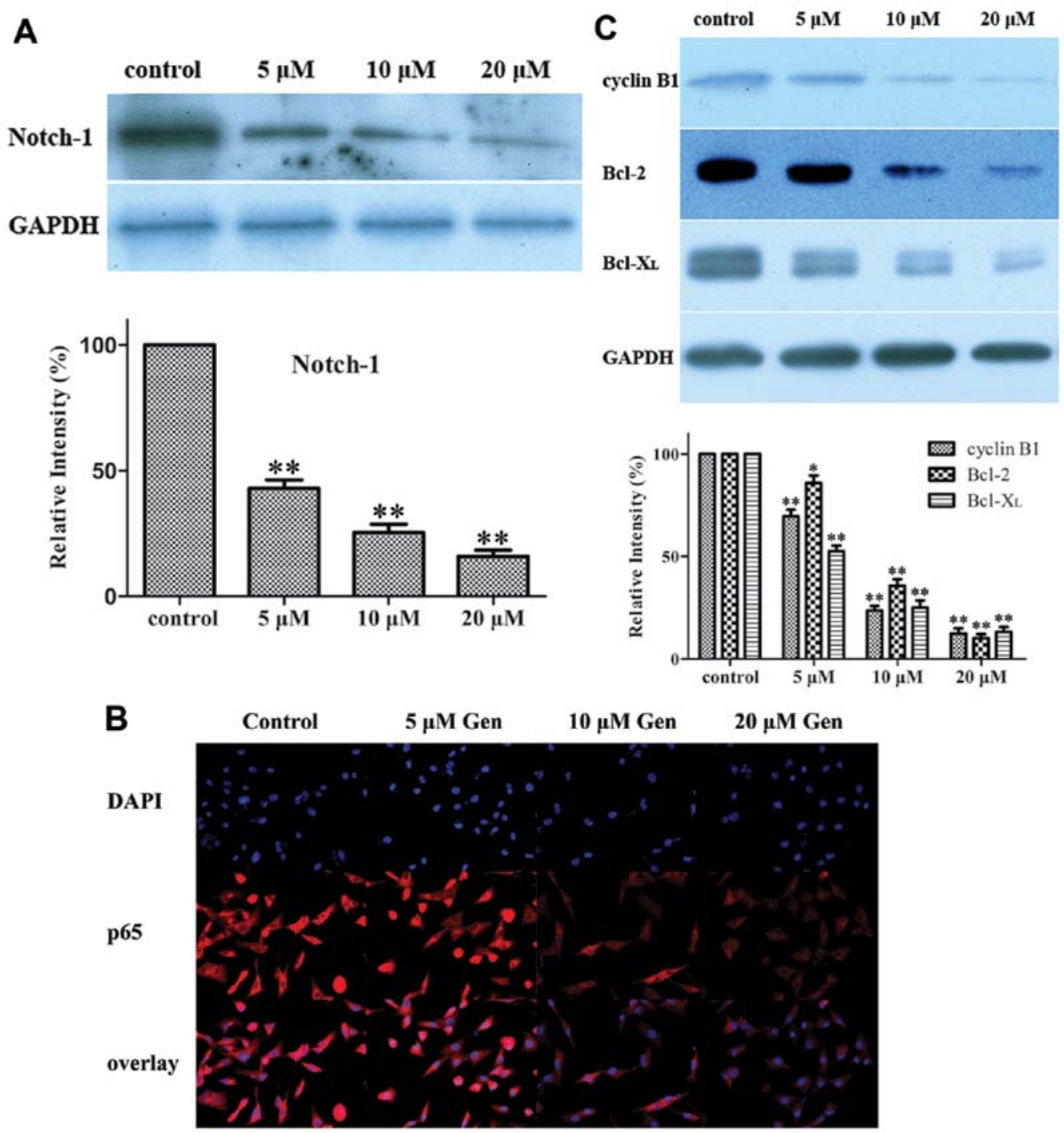

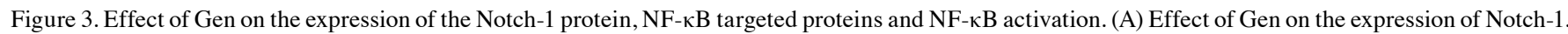
MDA-MB-231 cells were treated with $0,5,10,20 \mu \mathrm{M}$ Gen for $72 \mathrm{~h}$. Western blot analyses for the expression of Notch-1. GAPDH was used to normalize for protein loading. Histograms represent densitometric measurement of bands. Bars, mean $\pm \mathrm{SD},{ }^{*} \mathrm{P}<0.05,{ }^{* *} \mathrm{P}<0.01$, significantly different from the control. (B) Effect of Gen on NF-кB activation. MDA-MB-231 cells were seeded in a 6-well culture plate, and subsequently treated with $0,5,10,20 \mu \mathrm{M}$ Gen for $72 \mathrm{~h}$. After treatment, cells were incubated with p65 antibody and Cy3 fluorescein-conjugated secondary antibody, and nuclei were stained with DAPI. The images were obtained by confocal laser microscopy and overlay. The pink fluorescence indicates location of p65 protein in nuclei. (C) Effect of Gen on expression of NF- $\mathrm{\kappa B}$ targeted proteins. MDA-MB-231 cells were treated with 0, 5, 10, $20 \mu \mathrm{M}$ Gen for $72 \mathrm{~h}$. Western blot analyses for the expressions of cyclin B1, Bcl-2 and Bcl-xL were presented. GAPDH was used to normalize for protein loading. Histograms represent densitometric measurement of bands. Bars, mean $\pm \mathrm{SD}$, $\mathrm{P}<0.05$, ${ }^{* *} \mathrm{P}<0.01$, significantly different from control.

Gen $(0,5,10$ and $20 \mu \mathrm{M})$. We found that the protein level of Notch-1 was downregulated in MDA-MB-231 cells in a dosedependent manner (Fig. 3A).

Gen inhibits $N F-\kappa B$ activation and $N F-\kappa B$ targeted proteins. The nuclear translocation assay kit was used to determine NF- $\mathrm{kB}$ activation. The results showed that various concentrations of Gen can downregulate NF- $\kappa \mathrm{B}$ activation in MDA-MB-231 cells in a dose-dependent manner (Fig. 3B). Western blot analysis showed that the levels of NF- $\kappa \mathrm{B}$ targeted proteins, cyclin $\mathrm{B} 1, \mathrm{Bcl}-2, \mathrm{Bcl}-\mathrm{xL}$, were downregulated in MDA-MB-231 cells treated by Gen compared with the control cells (Fig. 3C).

$N F-\kappa B$ inactivation is mediated via the Notch-1 pathway. Both Notch-1 and NF- $\kappa$ B were downregulated by siRNA (Fig. 4). The transfection of Notch-1 siRNA into MDA-MB231 cells inhibited the translocation of NF- $\mathrm{KB}$ into the nucleus
(Fig. 5). The downregulation of Notch-1 and NF- $\kappa B$ expression by siRNA both inhibited the expression of cyclin B1, Bcl-2 and Bcl-xL (Fig. 4). These results suggest that NF- $\mathrm{BB}$ inactivation was mediated via the Notch-1 pathway.

\section{Discussion}

Our study reveals that Gen elicits a dramatic effect on cell growth inhibition in a dose-dependent and time-dependent manner. Gen induced MDA-MB-231 cell apoptosis and induced cell cycle arrested in the G2/M phase. On the other hand, we examined the mechanisms of the action of Gen on MDA-MB-231 cells. We demonstrated for the first time, to our knowledge, that in TNBC cells, inhibition of the activity of NF- $\kappa B$ via the Notch-1 pathway may be an important mechanism for growth inhibition by Gen. What's more, we found 

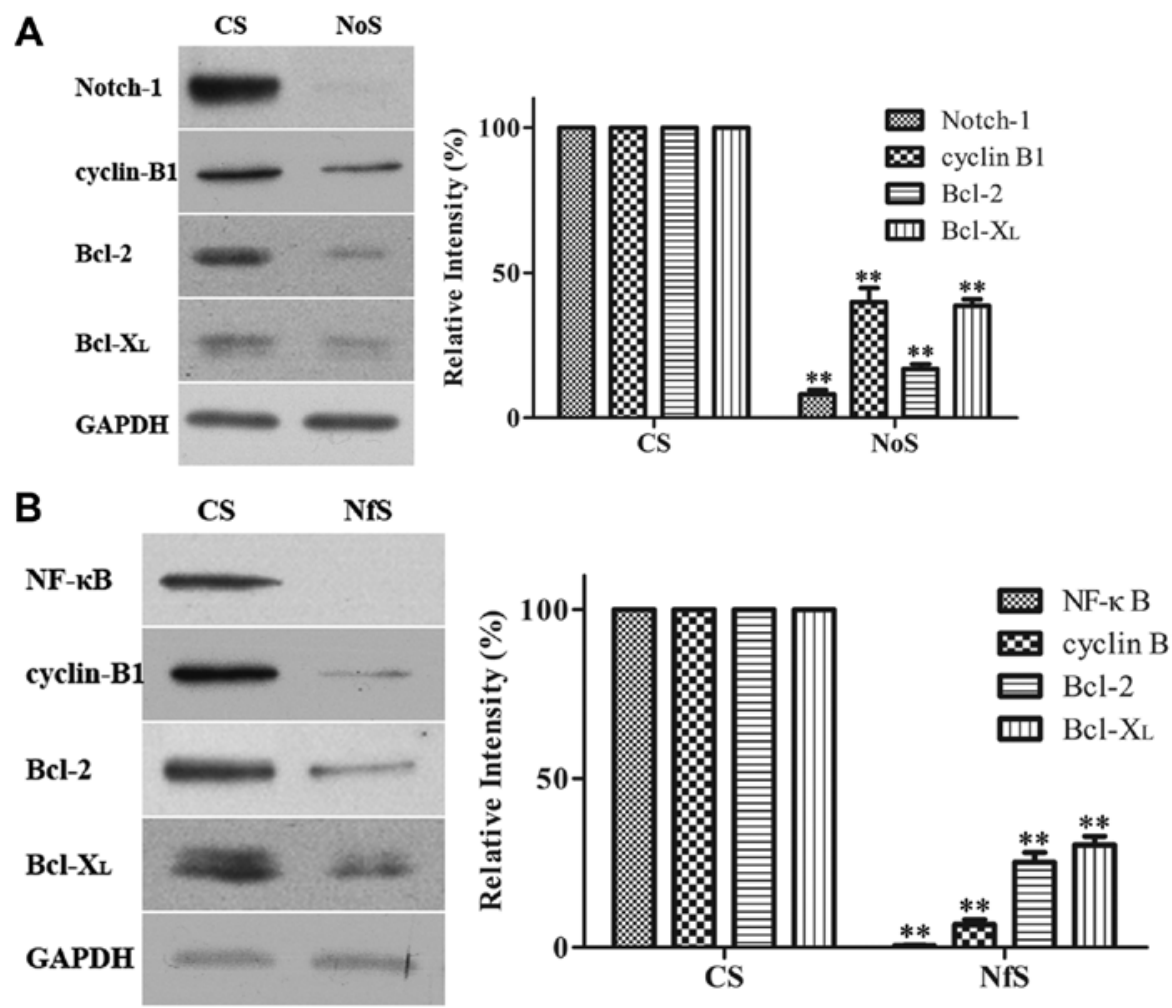

Figure 4. Effect of siRNA on the expression of several proteins. MDA-MB-231 cells were treated with Notch-1 siRNA, NF-kB siRNA, and siRNA control for $72 \mathrm{~h}$. Western blot analyses for the expression of proteins were presented. GAPDH was used to normalize for protein loading. Histograms represent densitometric measurement of specific bands using GAPDH levels as the control. Bars, mean $\pm \mathrm{SD},{ }^{*} \mathrm{P}<0.05,{ }^{* * *} \mathrm{P}<0.01$, significantly different from the control. (A) Downregulation of NF- $\kappa \mathrm{B}$ and its target gene cyclin B1, Bcl-2 and Bcl-xL by siRNA in MDA-MB-231 cells. NfS, NF-kB siRNA; CS, control siRNA. (B) Downregulation of Notch-1 and its target gene cyclin B1, Bcl-2 and Bcl-xL by siRNA in MDA-MB-231 cells. NoS, Notch-1 siRNA; CS, control siRNA. Inhibition of protein expression by Gen or siRNA in MDA-MB-231 cells.

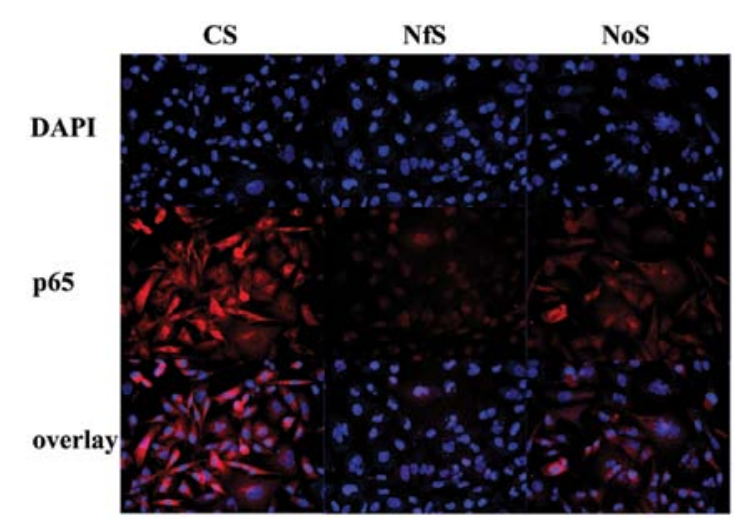

Figure 5. Effect of siRNA on NF- $\kappa B$ activity. After $72 \mathrm{~h}$ the cells were transfected with Notch-1 siRNA, NF- $\kappa B$ siRNA, or siRNA control and the effect

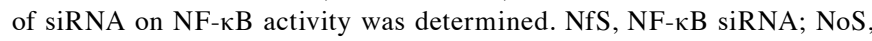
Notch-1 siRNA; CS, control siRNA.

that Gen downregulated the expression of cyclin $\mathrm{B} 1, \mathrm{Bcl}-2$ and Bcl-xL in MDA-MB-231 cells, possibly mediated by NF- $\mathrm{kB}$ activation via the Notch-1 signaling pathway. Based on the results, we speculate that Gen is a potential therapeutic agent for TNBC.

Gen, as one of the major soy isoflavones in soy products, is a relatively nontoxic natural agent. Apart from its efficiency, attention needs to be paid to its safety. Because of its structural similarity with $17 \beta$-estradiol, Gen has the capacity to bind to $\mathrm{ER} \alpha$ and induce hormone-like effects. Thus, at lower dose
$(<10 \mu \mathrm{M})$ Gen may stimulate $\mathrm{ER} \alpha^{+}$cell growth and entry into the cell cycle. However, there is no need to worry about these effects on TNBC cells, like MDA-MB-231 cells, in the present study. Notably, numerous epidemiological studies support a significant inverse association between soy isoflavones intake and risk of breast cancer incidence and recurrence. Gen may be a potential attractive therapeutic agent for TNBC.

The Notch pathway is an important transduction pathway in cancer cells, which is always aberrantly activated in breast cancer (19). Notch signaling is normally activated by ligand-receptor binding between two neighboring cells (20). It consists of Notch receptors (Notch-1-4), Notch ligands (Deltalike-1, $-3,-4$, and Jagged-1, -2) and CSL (DNA binding protein) (21). High-level co-expression of Notch-1 and Jagged-1 has been associated with poor overall survival (22-24). Based on previous studies, Notch signaling pathway plays a critical role in controlling breast cancer cell growth and apoptosis (25). Considering the CBF-1 transcriptional activity, reported by Rizzo et al (26), it is suggested that factors other than expression levels of Notch-1 regulate Notch-dependent reporter activity. A previous study demonstrated that the TNBC cell line MDA-MB-231 had much higher Notch-dependent reporter activity than the ER $\alpha^{+}$lines (MCF-7 and T47D) and Her2/ Neu overexpression line SKBR3. Importantly, the Notch-1 signaling pathway has been demonstrated to play a critical role in TNBC (14). It was reported that MDA-MB-231 xenografts were highly sensitive to the treatment of GSI, a Notch inhibitor (26). Therefore, the Notch-1 pathway is a rational target of 
breast cancer, especially for TNBC. We demonstrated for the first time, to our knowledge, that Gen inhibits the Notch-1 signaling pathway in MDA-MB-231 cells.

Additionally, NF- $\kappa \mathrm{B}$ is a putative target gene of activated Notch-1 (18). Numerous studies have documented elevated $\mathrm{NF}-\kappa \mathrm{B}$ DNA-binding activity in both mammary carcinoma cell lines and primary human breast cancer tissues (27-29). $\mathrm{NF}-\kappa \mathrm{B}$ controls breast cancer initiation, progression, metastasis, and resistance to chemotherapy (30). Our study reveals that various concentrations of Gen can downregulate $\mathrm{NF}-\kappa \mathrm{B}$ activation in a dose-dependent manner.

Translocation of NF- $\kappa \mathrm{B}$ into the nucleus can activate transcription of genes (31). We found that Gen downregulated expression of cyclin B1, Bcl-2 and Bcl-xL in MDA-MB-231 cells, possibly mediated by NF- $\kappa \mathrm{B}$, via the Notch-1 signaling pathway. Furthermore, our data suggests that knockdown of Notch-1 or NF- $\kappa$ B by siRNA leads to downregulation of cyclin $\mathrm{B} 1, \mathrm{Bcl}-2$ and Bcl-xL in MDA-MB-231 cells. Cyclin B1 is a cell cycle regulatory protein, which is overexpressed in breast cancer (32). Decreasing cyclin B1 expression inhibits proliferation and induces apoptosis in tumor cells (33). Bcl-2 protein is a member of the Bcl-2 family that regulates apoptosis, which is a potent inhibitor of apoptosis (34). As far as breast cancer is concerned, $\mathrm{Bcl}-2$ protein is generally expressed in $60-80 \%$ of invasive breast carcinoma $(35,36)$. To date, Bcl-xL, another member of the Bcl-2 family, has been shown to correlate with chemotherapy resistance of mammary tumors in a mouse model (37).

In conclusion, the results of our study demonstrate that Gen inhibits triple-negative breast cancer MDA-MB-231 cell growth by inhibiting NF- $\kappa$ B activity via the Nocth-1 signaling pathway. Our study gives strong evidence that Notch-1 is an attractive molecular target for the treatment of TNBC. Gen may be used alone or in combination, to achieve better treatment outcome of TNBC. Further preclinical and clinical studies should be performed to confirm the hypothesis to apply the use of Gen in patients with TNBC.

\section{Acknowledgements}

This study was mainly supported by the Foundation from Jiangsu provincial administration of traditional Chinese Medicine (LZ11079). This study was also supported in part by the National Natural Science Foundation of China (81071753 and 81172502), the Wu Jie-Ping Foundation (320.670010009), the Six Kinds of Outstanding Talent Foundation of Jiangsu Province (2010-ws-079 to W.H. and 2009 to Q.D.), the Science and Education for Health Foundation of Jiangsu Province (RC2007054), the Natural Science Foundation of Jiangsu Province (BK2009438, BK2010581, BK2011853 and BK2011855), the Program for Development of Innovative Research Team in the First Affiliated Hospital of NJMU (IRT-008), and a project funded by the Priority Academic Program Development of Jiangsu higher Education Institutions (PAPD).

\section{References}

1. Jemal A, Seige R, Xu J and Ward E: Cancer statistics, 2010. CA Cancer J Clin 60: 277-300, 2010.
2. Smith RA, Cokkinides V, Brooks D, Saslow D, Shah M and Brawley OW: Cancer screening in the United States, 2011: a review of current American Cancer Society guidelines and issues in cancer screening. CA Cancer J Clin 61: 8-30, 2011.

3. Lara-Medina F, Perez-Sanchez V, Saavedra-Perez D, et al: Triple negative breast cancer in Hispanic patients: high prevalence, poor prognosis, and association with menopausal status, body mass index, and parity. Cancer 117: 3658-3669, 2011.

4. Carey LA, Perou CM, Livasy CA, et al: Race, breast cancer subtypes, and survival in the Carolina Breast Cancer Study. JAMA 295: 2492-2502, 2006.

5. Dent R, Trudeau M, Pritchard KI, et al: Triple-negative breast cancer: clinical features and patterns of recurrence. Clin Cancer Res 13: 4429-4434, 2007.

6. Haffty BG, Yang Q, Reiss M, et al: Locoregional relapse and distant metastasis in conservatively managed triple negative early-stage breast cancer. J Clin Oncol 24: 5652-5657, 2006.

7. Rakha EA, EI-Sayed ME, Green AR, Lee AH, Robertson JF and Ellis IO: Prognostic markers in triple-negative breast cancer. Cancer 109: 25-32, 2007.

8. Tischkowitz M, Brunet JS, Begin LR, et al: Use of immunohistochemical markers can refine prognosis in triple negative breast cancer. BMC Cancer 7: 134, 2007.

9. Wu AH, Yu MC, Tseng CC and Pike MC: Epidemiology of soy exposures and breast cancer risk. Br J Cancer 98: 9-14, 2008.

10. Wu AH, Koh WP, Wang R, Lee HP and Yu MC: Soy intake and breast cancer risk in Singapore Chinese Health Study. Br J Cancer 99: 196-200, 2008.

11. Lee SA, Shu XO, Li H, et al: Adolescent and adult soy food intake and breast cancer risk: results from the Shanghai Women's Health Study. Am J Clin Nutr 89: 1920-1926, 2009.

12. Shu XO, Zheng Y, Cai H, Gu K, Chen Z, Zheng W and Lu W: Soy food intake and breast cancer survival. JAMA 302: 2437-2443, 2009.

13. Dong JY and Qin LQ: Soy isoflavones consumption and risk of breast cancer incidence or recurrence: a meta-analysis of prospective studies. Breast Cancer Res Treat 125: 315-323, 2011.

14. Li Z, Li J, Mo B, et al: Genistein induces cell apoptosis in MDA-MB-231 breast cancer cells via the mitogen-activated protein kinase pathway. Toxicol in Vitro 22: 1749-1753, 2008.

15. Li Z, Li J, Mo B, et al: Genistein induces G2/M cell cycle arrest via stable activation of ERK1/2 pathway in MDA-MB-231 breast cancer cells. Cell Biol Toxicol 24: 401-409, 2008.

16. Speiser J, Foreman K, Drinka E, et al: Notch-1 and Notch-4 biomarker expression in triple-negative breast cancer. Int J Surg Pathol: Nov 13, 2011 (Epub ahead of print).

17. Shih IeM and Wang TL: Notch signaling, gamma-secretase inhibitors, and cancer therapy. Cancer Res 67: 1879-1882, 2007.

18. Oswald F, Liptay S, Adler G and Schmid RM: NF-kappaB2 is a putative target gene of activated Notch-l via RBP-Jkappa. Mol Cell Biol 18: 2077-2088, 1998.

19. Stylianou S, Clarke RB and Brennan K: Aberrant activation of notch signaling in human breast cancer. Cancer Res 66: $1517-1525,2006$.

20. Gray GE, Mann RS, Mitsiadis E, et al: Human ligands of the Notch receptor. Am J Pathol 154: 785-794, 1999.

21. Gidzinska B: Notch1 receptor: structure and role during T-cell development. Postepy Hig Med Dosw 57: 369-376, 2003 (In Polish).

22. Reedijk M, Odorcic S, Chang L, et al: High-level coexpression of JAG1 and NOTCH1 is observed in human breast cancer and is associated with poor overall survival. Cancer Res 65: 8530-8537, 2005.

23. Reedijk M, Pinnaduwage D, Dickson BC, et al: JAG1 expression is associated with a basal phenotype and recurrence in lymph nodenegative breast cancer. Breast Cancer Res Treat 111: 439-448, 2008.

24. Dickson BC, Mulligan AM, Zhang H, Lockwood G, O'Malley FP, Egan SE and Reedijk M: High-level JAG1 mRNA and protein predict poor outcome in breast cancer. Mod Pathol 20: 685-693, 2007.

25. Miele L: Rational targeting of Notch signaling in breast cancer. Expert Rev Anticancer Ther 8: 1197-1202, 2008.

26. Rizzo P, Miao H, D'Souza G, et al: Cross-talk between notch and the estrogen receptor in breast cancer suggests novel therapeutic approaches. Cancer Res 68: 5226-5235, 2008.

27. Cogswell PC, Guttridge DC, Funkhouser WK and Baldwin AS Jr: Selective activation of NF-kappa B subunits in human breast cancer: potential roles for NF-kappa B2/p52 and for Bcl-3. Oncogene 19: 1123-1131, 2000. 
28. Nakshatri H, Bhat-Nakshatri P, Martin DA, Goulet RJ Jr and Sledge GW Jr: Constitutive activation of NF-kappaB during progression of breast cancer to hormone-independent growth. Mol Cell Biol 17: 3629-3639, 1997.

29. Sovak MA, Bellas RE, Kim DW, et al: Aberrant nuclear factor$\mathrm{kappaB} / \mathrm{Rel}$ expression and the pathogenesis of breast cancer. $\mathrm{J}$ Clin Invest 100: 2952-2960, 1997.

30. Nakshatri H and Goulet RJ Jr: NF-kappaB and breast cancer. Curr Probl Cancer 26: 282-309, 2002.

31. Chen LF, Fischle W, Verdin E and Greene WC: Duration of nuclear NF-kappaB action regulated by reversible acetylation. Science 293: 1653-1657, 2001.

32. Kawamoto H, Koizumi H and Uchikoshi T: Expression of the G2-M checkpoint regulators cyclin B1 and cdc2 in nonmalignant and malignant human breast lesions: immunocytochemical and quantitative image analyses. Am J Pathol 150: 15-23, 1997.

33. Yuan J, Yan R, Krämer A, Eckerdt F, Roller M, Kaufmann M and Strebhardt K: Cyclin B1 depletion inhibits proliferation and induces apoptosis in human tumor cells. Oncogene 23: 5843-5852, 2004.
34. Viatour P, Bentires-Alj M, Chariot A, Deregowski V, de Leval L, Merville MP and Bours V: NF-kappa B2/p100 induces Bcl-2 expression. Leukemia 17: 1349-1356, 2003.

35. Luna-Moré S, Casquero S, Pérez-Mellado A, Rius F, Weill B and Gornemann I: Importance of estrogen receptors for the behavior of invasive micropapillary carcinoma of the breast. Review of 68 cases with follow-up of 54. Pathol Res Pract 196: 35-39, 2000.

36. Wang S, Yang D and Lippman ME: Targeting Bcl-2 and Bcl-xL with nonpeptidic small-molecule antagonists. Semin Oncol 30: 133-142, 2003.

37. Liu R, Page C, Beidler DR, Wicha MS and Núñez G: Overexpression of $\mathrm{Bcl}-\mathrm{x}(\mathrm{L})$ promotes chemotherapy resistance of mammary tumors in a syngeneic mouse model. Am J Pathol 155: 1861-1867, 1999. 